\title{
Quantifying multiple-site compositional turnover in an Afrotemperate forest, using zeta diversity
}

\author{
Cang Hui ${ }^{1,2^{*}}$, Wessel Vermeulen ${ }^{3}$ and Graham Durrheim ${ }^{3}$
}

\begin{abstract}
Background: Species turnover is typically measured by partitioning diversity components into alpha and pairwise beta diversity. However, alpha and beta components cannot express the full spectrum of multiple-site compositional turnover. To this end, zeta diversity has been proposed as an extended framework to allow complete biodiversity partitioning and to measure multiple-site species turnover. We use a zeta-diversity framework to explore the turnover and potential community assembly processes of an African Montane Forest.

Methods: Using a $20 \mathrm{~m}$ grid, we explore the species turnover in a 4.55 ha forest plot located in the Garden Route National Park of South Africa, with 47 and 27 canopy and sub-canopy tree species in the regional pool. We first calculate how zeta diversity declines and how the probability of retention of species with particular occupancies changes with increasing zeta orders (i.e. the number of sites [grid cells] involved in the calculation). Using null models with row sums and column sums constrained respectively, we explore whether species turnover is driven by mechanisms of ecological differences (species-specific occupancies) or habitat heterogeneity (site-specific alpha diversity and thus environmental filters).
\end{abstract}

Results: The decline of zeta diversity with zeta order followed a power law; that is, the probability of retention increased with species occupancies, suggesting common species being more likely to be discovered in extra sites. The null model retaining row sums (species' occupancy) of the species-by-site matrix recreated perfectly the decline of zeta diversity, while the null model of habitat heterogeneity (retaining column sums) was rejected. This suggests that mechanisms driving species-specific occupancies (i.e. ecological differences between species) dictate the multi-site species turnover in the community. The spatial patterns of zeta diversity revealed little spatial structuring forces, supporting a fine-grain structure in these southern Cape forests.

Conclusions: The framework of zeta diversity revealed mechanisms driving the large discrepancies in the occupancy among species that are behind the species turnover in the African Montane forest plot. Future studies could further link species turnover to spatial distance decay. Environmental filters and temporal turnover from landscape demography could bring a cohesive understanding of community assembly in these unique forest ecosystems.

Keywords: Species turnover, Diversity partitioning, Zeta diversity, Community assembly, Southern cape forest, Afromontane forest

\footnotetext{
* Correspondence: chui@sun.ac.za

${ }^{1}$ Centre for Invasion Biology, Department of Mathematical Sciences,

Stellenbosch University, Matieland, Stellenbosch 7602, South Africa

${ }^{2}$ Mathematical and Physical Biosciences, African Institute for Mathematical

Sciences, Muizenberg 7645, South Africa

Full list of author information is available at the end of the article
} 


\section{Background}

Biodiversity patterns are formed by the co-distribution of resident species in space and time. Global and regional conservation relies on understanding the mechanisms that generate and maintain these biodiversity patterns (Condit et al. 2002; Myers \& LaManna 2016; Socolar et al. 2016), especially when facing mounting challenges from man-made environmental change, such as climate change, urbanisation and biological invasions (Latombe et al. 2017; Hui \& Richardson 2017). As the foundation of these biodiversity patterns, the species-bysite matrix allows the immediate measurement of biodiversity composition and turnover within and across sites so that changes can be traced, assembly processes tentatively inferred, and environmental drivers identified (Dornelas et al. 2014; McGill et al. 2015). To this end, measures of species compositional turnover over space and time, best known under the banner of beta diversity, have been rapidly developed over the past decades, with their performance hotly contested (Magurran \& Henderson 2010; Anderson et al. 2011; Shimadzu et al. 2015). Indeed, a good understanding of beta diversity could allow us to partition diversity into within- and between-site dissimilarity (i.e. alpha and beta components) (Jost et al. 2010; Tuomisto 2010). When combined with environmental and trait measures, such diversity partitioning allows us to differentiate drivers or sensitive traits that are crucial to maintain within-site species coexistence from those that are responsible to cross-site differentiation (Lebrija-Trejos et al. 2010; Hui et al. 2013; Latombe et al. 2017).

With these pairwise beta diversity metrics, we could still miss important information on the full spectrum of biodiversity, due to the inability of beta diversity to partition biodiversity of three or more sites (or communities). For instance, it is not possible to express biodiversity components that are unique to a particular site or shared by all sites. Moreover, pairwise turnover is predominately driven by missing or gaining those rare and satellite species between communities, whereas the widespread common species are often shared between communities thus contributing little to beta-diversity turnover. Beta diversity is thus biased towards turnover caused by rare species with a limited distribution. Studies on beta diversity are thus overemphasising the role of specific drivers (including chance) in determining the presence or absence of rare species, and missing the spatial drivers of common species that often dominate ecosystem functioning (McGill et al. 2015; McGeoch \& Latombe 2016). To this end, multiplesite similarity/dissimilarity measures have been developed (Koch 1957; Diserud \& Odegaard 2007; Baselga et al. 2007). However, these multiple-site metrics provide a composite summary of turnover across all sites that are difficult to interpret (Diserud \& Odegaard 2007; Ricotta \& Pavoine 2015). Because these metrics are largely a composite summary of alpha, beta and gamma components, they are sensitive to the number of sites concerned. For instance, with increasing sample size, Koch's and Disrerud \& Odegaard's metrics approach zero, while Baselga et al.'s metric approaches one, making them insensitive for comparing species turnover among large numbers of communities.

Zeta diversity was recently developed as a concept for quantifying the number of species shared by multiple sites (Hui \& McGeoch 2014). This metric allows us to calculate all components in multi-site diversity partitioning and provides a common currency for building and connecting other incidence-based diversity measures and patterns. Unlike incidence-based beta diversity metrics that are biased towards identifying the contribution of rare species to turnover, zeta diversity provides information on the full spectrum of rare to intermediate and common species as they contribute to driving compositional turnover. Instead of focusing on comparing multi-site metric performance, the concept of zeta diversity provides an alternative by embracing the n-dependency in multiple-site diversity partitioning (where $n$ represents the number of sites/communities), similar to the argument on embracing the scale-dependency in cross-scale diversity partitioning (Hui \& McGeoch 2007, 2008). Although zeta diversity has a number of conceptual and analytical advantages over related multiple-site diversity metrics, it has only just started to be used for quantifying and predicting biodiversity patterns in empirical data (Roura-Pascual et al. 2016; Roigé et al. 2016; Latombe et al. 2017; McGeoch et al. 2017; Vaz et al. 2017; Kunin et al. 2018). To this end, we will illustrate how the outputs from zeta diversity analyses can provide valuable and novel insights about the species turnover and community assembly processes in an Afromontane forest.

In particular, we aim to test whether the observed multi-site species turnover is driven primarily by ecological differences (e.g. species-specific occupancies) or by habitat heterogeneity (i.e. site-specific alpha diversity as a proxy of site quality). Community assembly can be in principle governed by four high level forces: dispersal, drift, selection and speciation (Vellend 2016), with environmental filters often identified as an important driver of community assembly in tropical forests (LebrijaTrejos et al. 2010). Although the neutral theory of ecological communities (Hubbell 2001) has successfully explained a number of community patterns, notably the lognormal-like relative abundance distribution (Volkov et al. 2003, 2007), it has failed to explain beta turnover in Panama and Amazonian forests (Condit et al. 2002). That is, the selection force (e.g. competition and consequently niche partitioning; Tilman 2004) that is missing in the neutral model could have driven the species turnover in 
those forests. Consequently, we further refine our search for signs of niche differentiation and competition dominance in driving observed ecological differences and species turnover. Specifically, we examine the parametric form of zeta diversity declining with zeta order (power law [signalling niche differentiation] versus negative exponential [signalling the dominance of stochastic force]; Hui \& McGeoch 2014).

\section{Methods}

\section{Data and study area}

Forest data have greatly contributed to the development of ecological theories and debates in the past (Condit et al. 2000; Hubbell 2001; Liang et al. 2016). Here, we intended to explore species turnover patterns in an Afromontane forest in the southern Cape, part of the largest forest complex in southern Africa (Von Maltitz et al. 2003; Mucina and Rutherford 2006). These forests are scattered on the narrow coastal strip south of the Outeniqua and Tsitsikamma mountain ranges (approximately $33^{\circ} 45^{\prime} \mathrm{S}$ latitude) and cover a total area of ca. $600 \mathrm{~km}^{2}$ (Geldenhuys 1991). The Southern Cape Forest enjoys high conservation status (Mucina and Rutherford 2006), with more than half of its extent located in the Garden Route National Park (GRNP). It comprises of 470 species that belong to 280 genera and 106 families (Geldenhuys 1993), of which 47 and 27 are canopy and sub-canopy species respectively. This relatively high richness has been attributed to the range of diverse habitat types and dispersal corridors that linked these forests to the Afromontane Eastern Escarpment (Geldenhuys 1992). Most of the canopy and sub-canopy tree species are widespread, and common or scattered in moist to dry forest. Regeneration is generally good, and mast fruiting occurs in several species (Von Maltitz et al. 2003). Most species are shade tolerant and locally persistent (Midgley et al. 1990).

The study area forms part of the Diepwalle Forest Dynamics Research Site, also known as the Diepwalle French Volume Curve (FVC) Research Area, which was established in 1937 and located to the north of the town of Knysna on the southern coastline of South Africa, at $33^{\circ} 56^{\prime} \mathrm{S}, 23^{\circ} 09^{\prime} \mathrm{E}$ (Gadow et al. 2016). The site is at an altitude of $400 \mathrm{~m}$ above mean sea level and has a predominantly southerly to south-westerly aspect. The climate can be described as moist, warm temperate. Rain occurs throughout the year, usually with peaks during the autumn and spring months. The mean annual rainfall at Diepwalle is about $1200 \mathrm{~mm}$. The summers are warm (mean daily maxima $23.2{ }^{\circ} \mathrm{C}$ ) and winters mild $\left(16.6{ }^{\circ} \mathrm{C}\right)$. The site was used until 1954 for testing experimental management systems, but no further treatments have been applied since. The current forest dynamics monitoring programme was initiated in 1972 when all trees with a diameter at breast height (dbh) of $10 \mathrm{~cm}$ and greater were numbered, the species identified and the diameters measured and recorded. The point of measurement was permanently marked by means of a painted line (Van Daalen 1991). Areas covering a total of 67.7 ha and containing more than 50,000 trees have been re-measured periodically and have been managed as part of the Garden Route National Park since 2005.

This study makes use of 1987 data, covering an area of 4.56 ha (approximately $380 \mathrm{~m}$ by $120 \mathrm{~m}$ ) with the main canopy 18 to $22 \mathrm{~m}$ high (Van Daalen 1991). The forest plot contains 3215 trees of 25 species (Fig. 1), with Olea capensis subsp. marcocarpa the most common canopy species (731 individuals). It is slow growing and shade tolerant (Van Daalen 1991). Flowers are self-pollinated and by insects, and fruit dispersed by birds and mammals, with mast fruiting events often occurring (Von Maltitz et al. 2003). The top 5 most abundant species account for $72 \%$ of the total number of individuals. We divided the forest plot into 114 sites using a $20 \mathrm{~m}$ grid mesh and conducted zeta diversity analyses for the matrix of 25 species by 114 sites (Fig. 1 ).

\section{Zeta diversity}

Similar to alpha and beta diversity, zeta diversity can be used in a variety of analyses so to capture multiple facets of biodiversity. Simply put, zeta diversity of $\mathrm{n}$ sites, $\zeta_{n}$ (using the lower case Latin letter of zeta), is defined as the number of species shared by $\mathrm{n}$ sites, with $n$ named zeta order hereafter (Hui \& McGeoch 2014). Computation can be easily implemented by using the R package zetadiv (Latombe et al. 2016). By definition zeta diversity declines with zeta order. For instance, $\zeta_{1}$ is the average number of species in one site (alpha component), and $\zeta_{2}$ is the average number of species shared by any two sites ( $\zeta_{1}-\zeta_{2}$ normally represents beta component). Because species shared by $n+1$ sites are a subset of species shared by $n$ sites, the ratio of zeta diversity of adjacent orders $\left(\zeta_{n+1} / \zeta_{n}\right)$ represents the probability of retention that a species already shared by $\mathrm{n}$ sites is also expected to occur in one extra site, or equivalently that the proportion of species known to occur in $\mathrm{n}$ sites is also shared by $n+1$ sites. This probability of retention tells us the chance of a species with a particular level of occupancy (e.g. occurred in $n$ sites) occurring in an extra site. By calculating spatially explicit zeta diversity, say, using the moving window technique, we could visualise and identify how species similarity decays with geographical distance or environmental gradients, reflecting the distance decay patterns named isolation by distance and isolation by resistance, respectively (e.g. BerthoulySalazar et al. 2013). Key variables can then be identified using multivariate statistics, such as multi-site generalised dissimilarity modelling (Latombe et al. 2017), to 


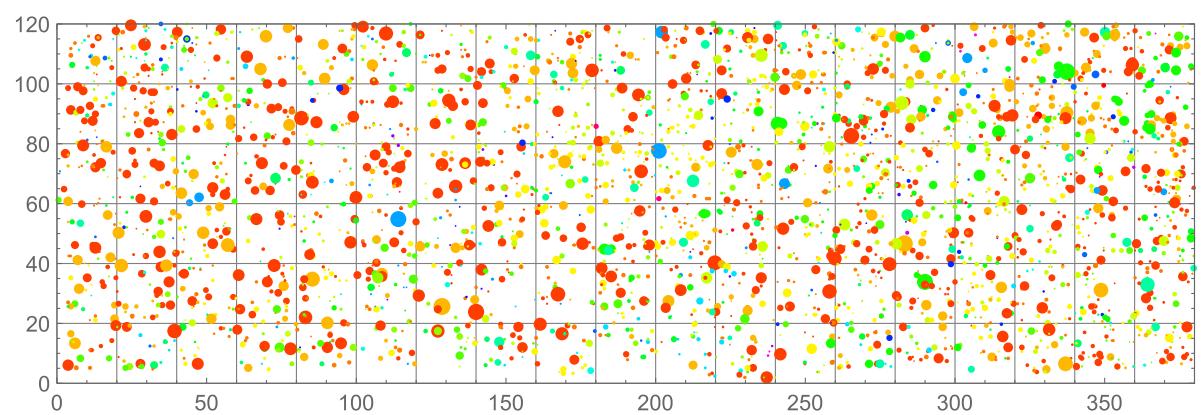

Fig. 1 A snapshot of the 3215 individual stems of 25 species. Different colours represent separate species and size proportional to the diameter at breast height, overlaid with a 20 m-resolution grid mesh, in the forest plot of the Diepwalle State Forest surveyed in 1987 used in this study

discern different combinations of determinants behind species turnover driven by species of different levels of occupancy.

We used two null models to test drivers of species turnover (measured by zeta diversity of different orders). The two null models permute elements of the speciesby-site (row $\times$ column) matrix of species occurrence (1: presence; 0: absence) under constraints of keeping the observed row sums or column sums the same as observed (Gotelli \& Graves 1996). When the row sums were kept, significant difference between the observed zeta diversity turnover and the null model expectation would signal mechanisms other than those determining ecological differences (here, species occupancies; i.e. row sums) driving the multi-site species turnover in the community. When the column sums were kept, significant difference between the observation and the null model expectation would suggest mechanisms other than those determining local species richness (most possibly site/habitat heterogeneity) driving the multi-site species turnover. As has often been argued in the literature that abiotic gradients between sites (and thus environmental filters) are the primary drivers of species turnover (e.g. Lebrija-Trejos et al. 2010; Soininen 2010), we should expect to see that the observed zeta turnover pattern conforms to the null model expectation with column sums constrained. Alternatively, more common species are increasingly more likely to be shared among sites (see the scale-heritage assumption; Fig. 2 in Hui \& McGeoch 2008), which predicts that species turnover driven more by ecological differences of occupancy frequencies and thus expecting the observed pattern to conform to the null model with row sums constrained.

To further infer the possible mechanisms behind the likely ecological differences between species that drive species turnover in the community, we explored the parametric form of zeta diversity decline. Zeta diversity normally declines with increasing zeta order in two forms: power law and negative exponential (Hui \& McGeoch 2014). A power law decline signals niche differentiation between species (e.g. species A is more likely to occur in site 1 than in site 2 , while species B prefers site 2 over site 1). A negative exponential decline represents stochastic occurrence, even when sites are heterogeneous (hosting different alpha diversities). Once the parametric form of zeta diversity decline is determined, we could further calculate a species accumulation curve and thus estimate species richness in the regional pool through extrapolating the total number of species by extending the number of sites $\mathrm{n}$ to a large number (Hui \& McGeoch 2014). When the decline of zeta diversity follows the negative exponential form, the zeta-based richness estimator becomes the same as the incidence-based Chao II estimator which estimates richness based on the frequency of singletons and doubletons in samples. However, the zeta-based richness estimator allows us to calculate the expected richness

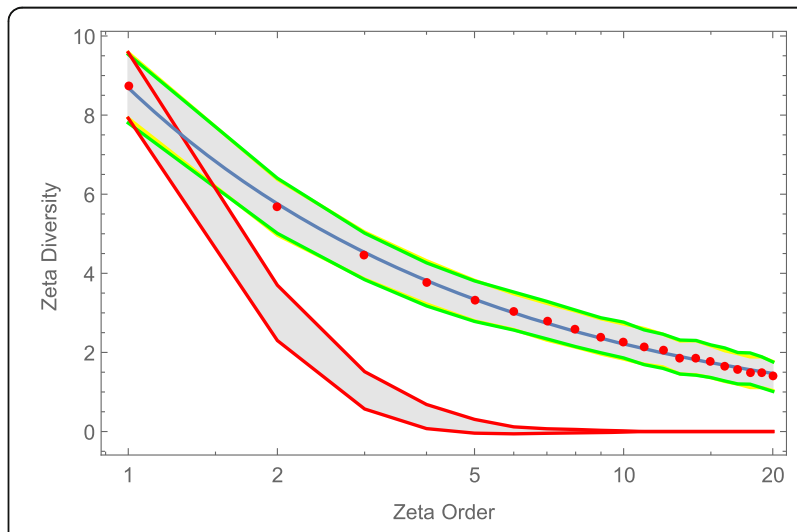

Fig. 2 Zeta diversity declines with zeta order. Zeta diversity represents the average number of shared species (red dots; grey band with yellow bounds: \pm 0.5 Standard deviation); zeta order represents the number of sites in the calculation of zeta diversity. Green curves represent the \pm 0.5 Standard deviation range of zeta diversity from the null model (1000 runs) keeping row sums (species occupancy) the same as observed. Red curves represent the \pm 0.5 Standard deviation range of zeta diversity from the null model (1000 runs) keeping column sums (site richness [habitat heterogeneity]) the same as observed. The observed zeta diversity decline follows a power law (blue curve) 
when the decline does not follow the negative exponential form and when all resident species are relative common (i.e. lacking of either singletons or doubletons in samples).

\section{Results}

We calculated zeta diversity for the first 20 zeta orders, with the mean and standard deviation steadily declining from $\zeta_{1}=9.39 \pm 1.68, \zeta_{2}=6.19 \pm 1.39$, to $\zeta_{5}=3.80 \pm 1.06$, $\zeta_{10}=2.55 \pm 0.96$ and $\zeta_{20}=1.62 \pm 0.85$ (Fig. 2). Importantly, the null model that constrained the row sums predicted perfectly the species turnover patterns, while the null model that constrained the column sums underestimated the zeta diversity at higher orders (Fig. 2), with the null model expectation close to zero at order 5 . Consequently, we can argue that species turnover in this community is completely determined by factors of ecological differences (species occupancies) and has little to do with site/habitat heterogeneity. Moreover, the probability of retention increased with zeta order and increased to above 0.9 for species occupying more than 5 sites (Fig. 3), indicating that common species are more likely to occur than rare species on extra sites and thus signalling ecological differences between species with different levels of occupancy.

Spatial mapping of zeta diversity for the Afromontane forest plot supported the claim on the insignificant effect of habitat heterogeneity on species turnover, by revealing the fine-grain structure and thus little noteworthy spatial patterns (Fig. 4). However, looking closely, we can see that areas with greater higher-order zeta diversity, representing locally common species in the calculation (when using the moving window technique; e.g. see lighter areas in Figs. 4c and d), seemingly coincides with areas of high alpha diversity (local species richness; lighter areas in Fig. 4a). However, after normalising higher-

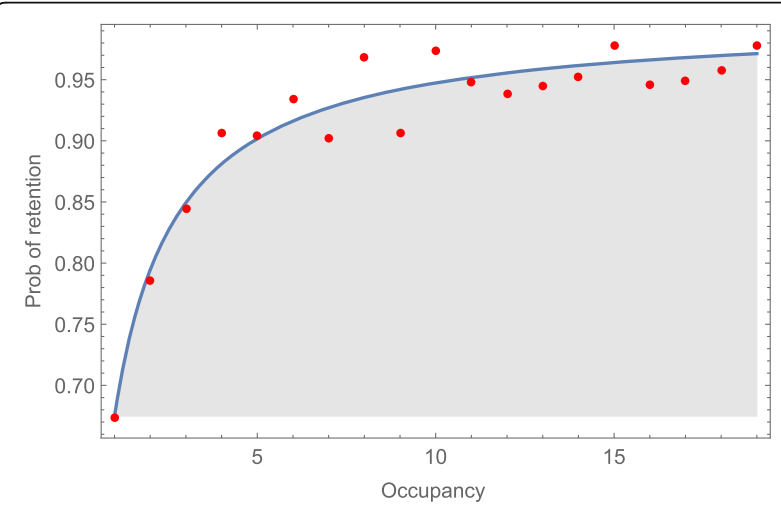

Fig. 3 Probability of retention for species of a given level of occupancy. The probability is calculated as $\zeta_{n+1} / \zeta_{n}$ (red dots), representing the probability that a species of a given level of occupancy $(n)$ will be retained in one extra site. The blue curve represents the prediction from the power law decline of zeta diversity (see Fig. 4) order zeta diversity by local alpha diversity (i.e. the proportion of locally common species; Fig. 4h), the above assertion seems disappeared: areas with many locally common species (Fig. 4c) do not overlap well with areas having a higher proportion of locally common species (Fig. 4h). This could be explained by the spatially contrasting probability of retaining species at different local levels of commonness (Fig. 4e-g). For instance, it is more likely that a locally rare species is retained than a locally common species in the top-left corner of the landscape (compare top-left corner of Fig. 4e with Fig. 4g). Consequently, we suspect that fine-scale processes such as seed dispersal/recruitment with a characteristic scale of 20 to $50 \mathrm{~m}$ could be driving such a fine-grained community structure.

As factors of species occupancies, other than habitat heterogeneity, determine the pattern of species turnover in this community, we further explored the parametric form of zeta diversity declining with zeta order. The decline of zeta diversity with zeta order followed closely a power law (Fig. 2), $\zeta_{n}=9.432 \cdot n^{-0.567}, R^{2}>0.999$, AICc $=$ -49.06; nonlinear least squares), instead of the negative exponential form $\left(R^{2}=0.956\right.$, AICc $\left.=51.42\right)$, supporting the assumption of a non-stochastic assembly force. We noticed that the exponent of the power law (0.567) lies within but close to the lower bound (0.38) of the $95 \%$ confidence intervals for reported communities in literature (Hui \& McGeoch 2014). Using the richness estimator derived from the framework of zeta diversity, we estimated 25.83 species in 128 samples (note, there are 25 species observed in 114 samples [sites] of the entire forest plot), 31.05 species in 41 ha, 40.20 species in $52.43 \mathrm{~km}^{2}$, and 43.11 species in $419.43 \mathrm{~km}^{2}$ (Fig. 5).

\section{Discussion and conclusions}

We have derived three propositions from the zeta diversity analysis of the forest snapshot data: (i) species turnover in this community is completely determined by factors driving ecological differences of species occupancies, and has little to do with site/habitat heterogeneity; (ii) non-stochastic assembly force, although not clearly identified in this study, could explain the increasing probability of retention of locally more common species; (iii) fine-scale processes such as seed dispersal/recruitment with a characteristic scale of 20 to $50 \mathrm{~m}$ could be driving such fine-grained community structures. These three propositions are consistent with results on community assembly in Afromontane forests. Indeed, although still poorly understood in these forests, the non-stochastic force of competition between trees of different species plays an important role in forest dynamics (Van Daalen 1993), with the growth of most species below the canopy influenced more by crown form and less by crown position. Canopy and sub-canopy species 

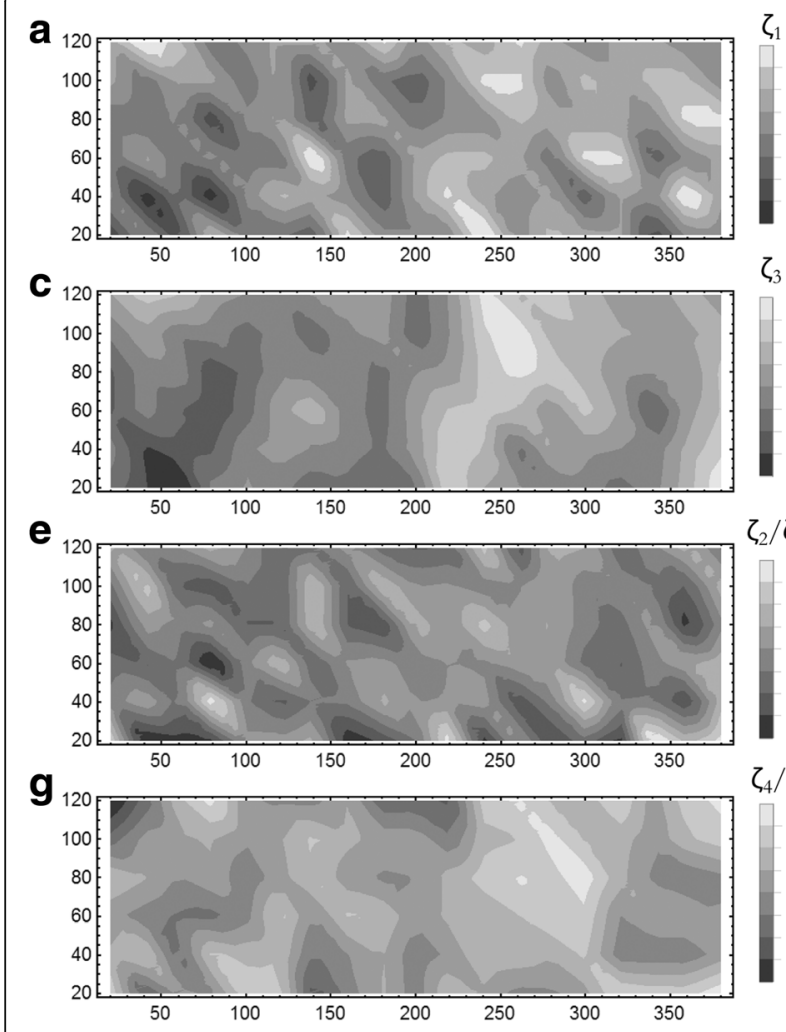
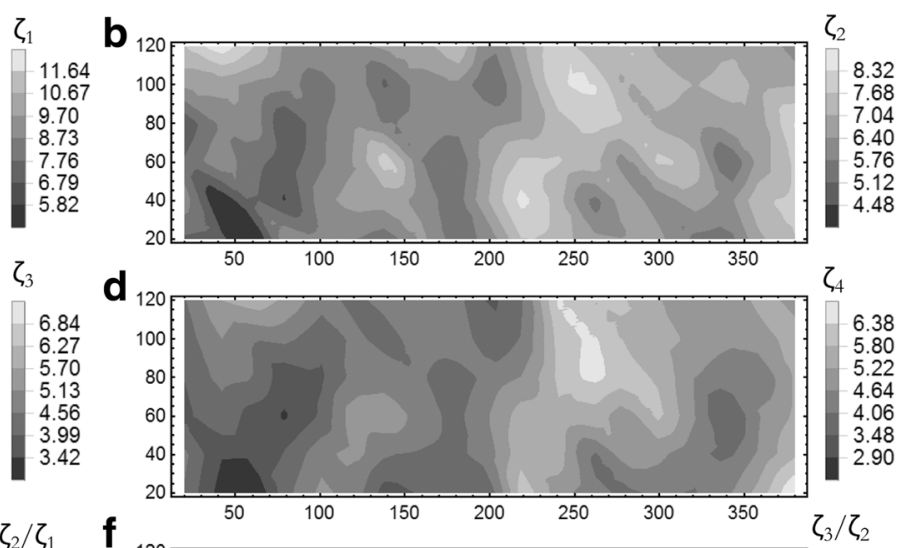

$\zeta_{2} / \zeta_{1}$
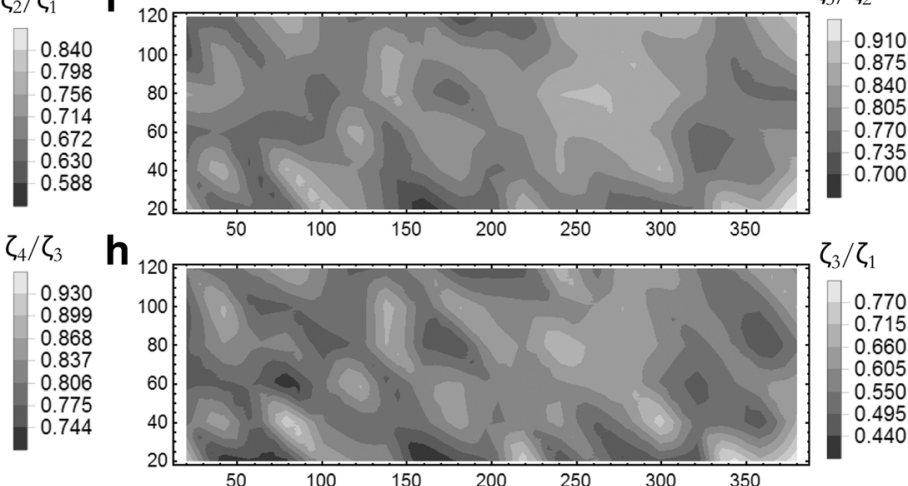

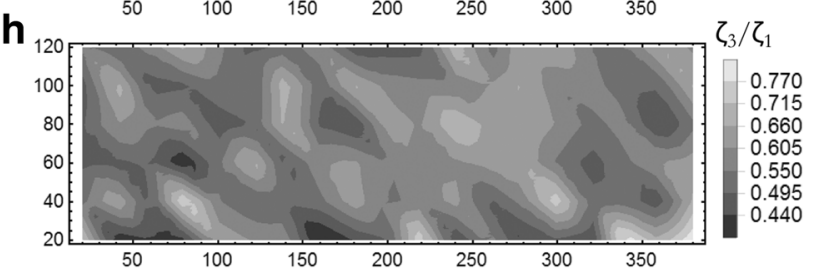

Fig. 4 Spatial patterns of local zeta diversity. a-d local zeta diversity of zeta order 1 to 4 , respectively; e-g the probability of retention $\left(\zeta_{n+1} / \zeta_{n}\right)$ for zeta order 1 to 3 ; $\mathbf{h}$ normalised zeta diversity (local zeta diversity of order 3 divided by local zeta diversity of order 1 [i.e. by local alpha diversity])

display distinct differences in their reactions to competition (Seifert et al. 2014). Growth is strongly influenced by light availability for canopy species in the lower canopy and subcanopy levels, while trees at the canopy level of inherently faster growing species usually reach larger

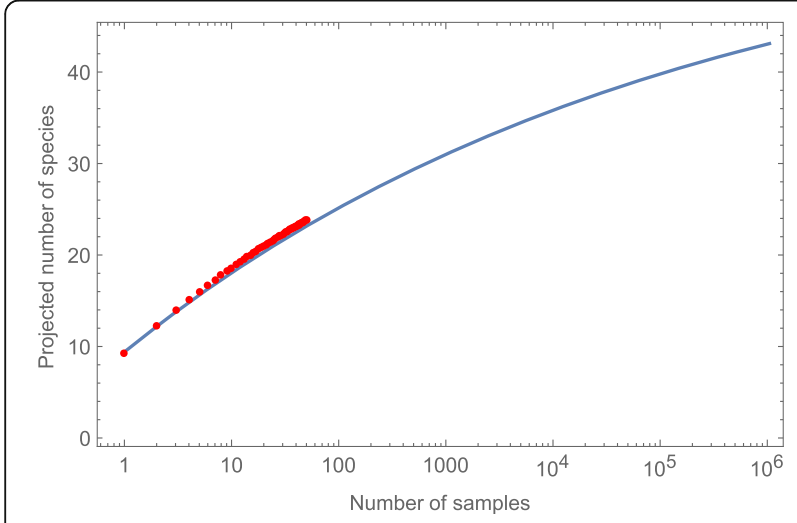

Fig. 5 Estimated number of species from zeta diversity (curve) and observed species accumulation curve (red dots). Note, due to the commonness of the species (lacking of singletons or doubletons), traditional species richness estimators (e.g. Jack-knife or the Chao II estimator) cannot be used for the dataset. Sample grain is $20 \mathrm{~m} \times$ $20 \mathrm{~m}$, and the extent of $10^{6}$ samples represents an area of $400 \mathrm{~km}^{2}$ sizes and are more responsive to light, with slower growing species occurring below faster growing species and vice versa (Seydack et al. 2011). The growth of subcanopy trees of canopy species is also constrained by the proximity of adult trees of the same species, particularly for the two dominant canopy species, viz. Olea capensis subsp. macrocarpa and Podocarpus latifolius (Seydack 2000). Moreover, species-level analyses of southern Cape forests in the region abound on regeneration and competition (e.g. Midgley et al. 1990; Seifert et al. 2014) and have revealed the pattern of being fine grained indicating that current tree canopy species in a mixed stand can regenerate under the same canopy (Geldenhuys 2009). Most of the canopy tree species in the forests are shade tolerant and can regenerate and establish continuously without major disturbances (except for Olinia ventosa), with the ironwood Olea capensis subsp. macrocarpa dominating both the canopy and regeneration of the fine-grain platform forests, where the disturbance regime is regular, generally with small, natural gaps (Geldenhuys \& Maliepaard 1983; Midgley et al. 1995).

As a side-line contribution, due to the lack of rare species (e.g. singletons and doubletons), zeta diversity framework still allows us to extrapolate and estimate the number of species in the regional species pool (Fig. 5). 
This extrapolation is obviously not a process-based method but based on extending zeta diversity to higher orders using the observed power law. As higher order zeta diversity is only a subset of lower order ones, this declining trend constrains the variation of zeta diversity at higher orders and in turn makes extrapolation of higher order zeta diversity less problematic. Importantly, the formulation of zeta diversity allows the use of any forms of zeta diversity decline for extrapolation. Such non-process based methodology emphasizes on crossscale pattern consistency and constraints (e.g. Hui et al. 2006; Hui 2009; Harte 2011) and has been shown to outperform many process-based methods for inferring fine scale occupancies and abundances (Hui et al. 2009; Barwell et al. 2014). Such inferences reflect the most probable or likely predictions without additional information/processes assumed. Specifically, the estimator of regional species richness from zeta diversity (Hui \& McGeoch 2014) is mathematically related to the theory of finite differences (Ruiz 1996). Zeta diversity for upscaling extrapolation has been compared to more than ten species-area methods and performed reasonably well (Kunin et al. 2018). To this end, we would advocate the use of zeta diversity as a new or unified framework of formulating macroecological patterns, rather than a specific structure or turnover metric, for biodiversity upscaling and partitioning.

We intend to propose zeta diversity as a common language or set of bricks for building the full spectrum of biodiversity structures, but not to specify what the biodiversity structures should look like. Arguably, such non-process based methods could only provide the bound estimates for realised patterns. Obviously, community assemblage patterns are driven by the four high-level processes (Vellend 2016): speciation, drift, dispersal, and selection. However, these four processes could manifest into a plethora of theories, such as the neutral theory which emphases only the drift, dispersal and the possibility of speciation in a metacommunity (Hubbell 2001) and can explain observed skewed species abundance distributions (Volkov et al. 2003, 2007). Such process-based models could further support specific estimations within the derived pattern-based bounds. To date, the marriage between pattern and process based methods has yet to produce cohesive and practical joint theories, largely due to the conundrum in process-topattern projection (not simply 1-to-1; rather, could often be 1-to-many and many-to-1).

We only studied a snapshot of the forest community, where the Afromontane community exhibits a rather fine-scale pattern or the lack of notably spatial structure. As a promising future research area, considering more realistic temporal and recruitment dynamics at landscape scales could be fruitful (Condit et al. 2006), for instance using the framework of landscape demography (Hui et al. 2017) which could handle the covariance in local patch dynamics caused by both dispersal and the Moran effect. Indeed, many works have pointed toward the role of demographic rates in space and time as the potential framework for unifying community assemblage patterns and methods (Law et al. 2003; Condit et al. 2006). Extending the zeta diversity framework from a platform of spatial turnover analysis to temporal turnover investigation is an ongoing research area. The extremely slow rate of zeta diversity decline in this community suggests a number of extremely common species dominating the landscape, while the rare species could have a large temporal turnover across years. In particular, the four most common species Ironwood (Olea capensis subsp. Macrocarpa), Kamassi (Gonioma kamassi), Real Yellowwood (Podocarpus latifolius) and Assegai (Curtisia dentata), were also most common in the community in 1972 (15 years before the current survey). In contrast, the 10 most rare species include White Silky Bark (Cassine eucleiformis), Cape Plane (Ochna arborea), Wild Pomegranate (Burchellia bubalina), Cape Beech (Rapanea melanophloeos), Coalwood (Lachnostylis hirta), Cape Holly (Ilex mitis), Dune Olive (Olea exasperata), and three newly emerged species in 1987: Cape Pock-ironwood (Chionanthus foveolatus), Glossyleaf (Rhamnus prinoides) and Wild Gardenia (Rothmannia capensis). Three rare species found in 1972 disappeared in the 1987 community: Hard Pear (Olinia ventosa), Wild Peach (Kiggelaria africana) and White Alder (Platylophus trifoliatus). In particular, Olinia ventosa is fast-growing and regarded to be more light demanding, requiring bigger disturbances for establishment. This could explain its absence during the 1987 re-measurement. As predicted from the zeta diversity framework (Fig. 5), the probability of retention for rare species (roughly occupancy $<5$ sites) is much lower than for common ones (occupancy greater than 100 sites). This suggests that conservation planning should differentiate common from rare species as different processes could drive their recruitment and persistence.

By extending the pairwise diversity partitioning into alpha and beta components, the framework of zeta diversity, together with standing tools in community ecology, provides a more complete picture of how diversity is organised in a community. Importantly, zeta diversity allows us to differentiate the role of common versus rare species in driving the compositional turnover patterns, as well as the potentially different sets of environmental determinants behind species turnover [not explored here]. This provides a more refined target and tool for conservation planning. The spatial analysis of zeta diversity points towards some potential of spatially refined site-based conservation planning to balance the conservation of species-rich sites versus sites with more locally 
common (or rare) species. Indeed, of the five management programmes in the management plan for the Garden Route National Park (SANParks 2012), the Terrestrial Vegetation Conservation Programme is aimed at ensuring the long-term persistence of biodiversity patterns and processes, enabling natural variation in structure, function and composition over space and time, and the Species of Special Concern Programme of SanParks is aimed to identify and maintain viable populations of selected species. These management programmes are supported by a research and monitoring programme, with forest dynamics, forest gap dynamics, forest fire disturbance, vegetation surveys and species of special concern, together with the sustainable use of timber and nontimber forest products, representing important focus areas for forest research (McGeoch et al. 2011; SANParks 2014). Our results further emphasise the potential and necessity of developing different target-species strategies for conserving common versus rare species, and target-site strategies for conserving species-rich sites versus sites with disproportionally more locally common or rare species. Specific objectives (e.g. conserving alpha diversity versus ensuring a certain level of species turnover) may demand different strategies.

\begin{abstract}
Acknowledgements
We are grateful to Klaus v. Gadow and Hui Li for inviting, organising and sponsoring the 2017 Forest Ecosystems Spring Workshop, to Pierre Legendre, Jingjing Liang and many others for interesting discussions during the workshop, and to Richard Condit and two anonymous reviewers for constructive suggestions. CH is supported by the National Research Foundation (NRF grants 89967 and 109244) the South African Research Chair Initiative. SANParks provided access to the data. Many people have contributed to the establishment, maintenance and re-measurement of the study site and management of the data base over a period of 45 years.
\end{abstract}

\section{Funding}

National Research Foundation of South Africa (grants 89967 and 109244).

\section{Authors' contributions}

$\mathrm{CH}$ performed data analyses. WV and GD collected and prepared field data. All authors contributed to the writing of the manuscript. All authors read and approved the final manuscript.

\section{Completing interests}

The authors declare that they have no competing interests.

\begin{abstract}
Author details
${ }^{1}$ Centre for Invasion Biology, Department of Mathematical Sciences, Stellenbosch University, Matieland, Stellenbosch 7602, South Africa. ${ }^{2}$ Mathematical and Physical Biosciences, African Institute for Mathematical Sciences, Muizenberg 7645, South Africa. ${ }^{3}$ Garden Route Scientific Services, South African National Parks, Knysna 6570, South Africa.
\end{abstract}

Received: 4 October 2017 Accepted: 13 February 2018

Published online: 16 February 2018

\section{References}

Anderson MJ, Crist TO, Chase JM, Vellend M, Inouye BD, Freestone AL, Harrison SP (2011) Navigating the multiple meanings of $\beta$ diversity: a roadmap for the practicing ecologist. Ecol Lett 14:19-28

Barwell LJ, Azaele S, Kunin WE, Isaac NJB (2014) Can coarse-grain patterns in insect atlas data predict local occupancy? Divers Distrib 20:895-907
Baselga A, Jiménez-Valverde A, Niccolini G (2007) A multiple-site similarity measure independent of richness. Biol Lett 3:642-645

Berthouly-Salazar C, Hui C, Blackburn TM, Gaboriaud C, van Rensburg BJ, van Vuuren BJ, Le Roux JJ (2013) Long-distance dispersal maximizes evolutionary potential during rapid geographic range expansion. Mol Ecol 22:5793-5804

Condit R, Ashton P, Baker P, Bunyavejchewin S, Gunatilleke S, Gunatilleke N, Hubbell SP, Foster RB, Itoh A, LaFrankie JV, Lee HS, Losos E, Manokaran N, Sukumar R, Yamakura T (2000) Spatial patterns in the distribution of tropical tree species. Science 288:1414-1418

Condit R, Ashton P, Bunyavejchewin S, Dattaraja HS, Davies S, Esufali S, Ewango C, Foster R, Gunatilleke IAUN, Gunatilleke CVS, Hall P, Harms KE, Hart T, Hernandez C, Hubbell S, Itoh A, Kiratiprayoon S, LaFrankie J, de Lao SL, Makana J-R, Noor MNS, Kassim AR, Russo S, Sukumar R, Samper C, Suresh HS, Tan S, Thomas S, Valencia R, Vallejo M, Villa G, Zillio T (2006) The importance of demographic niches to tree diversity. Science 313:98-101

Condit R, Pitman N, Leigh Jr EG, Chave J, Terborgh J, Foster RB, Núñez P, Aguilar S, Valencia R, Villa G, Muller-Landau HC, Losos E, Hubbell SP (2002) Beta-diversity in tropical forest trees. Science 295:666-669

Diserud OH, Odegaard F (2007) A multiple-site similarity measure. Biol Lett 3:20-22

Dornelas M, Gotelli NJ, McGill B, Shimadzu H, Moyes F, Sievers C, Magurran AE (2014) Assemblage time series reveal biodiversity change but not systematic loss. Science 344:296-299

Gadow K, Zhang GQ, Durrheim G, Drew D, Seydack A (2016) Diversity and production in an Afromontane Forest. Forest Ecosyst 3:15. https://doi.org/10.1186/ s40663-016-0074-7

Geldenhuys CJ (1991) Distribution, size and ownership of forests in the southern cape. S Afr J Forestry 158:51-66

Geldenhuys CJ (1992) Richness, composition and relationships of the flora of selected forests in southern Africa. Bothalia 22:205-233

Geldenhuys CJ (1993) Floristic composition of the southern cape forest flora with an annotated checklist. S Afr J Botany 59:26-44

Geldenhuys CJ (2009) Managing forest complexity through application of disturbancerecovery knowledge in development of silvicultural systems and ecological rehabilitation in natural forest systems in Africa. J For Res 15:3-13

Geldenhuys CJ, Maliepaard W (1983) Causes and sizes of canopy gaps in the southern cape forests. S Afr Forestry J 124:50-55

Gotelli NJ, Graves GR (1996) Null models in ecology. Smithsonian Institution Press, Washington

Harte J (2011) Maximum entropy and ecology: a theory of abundance, distribution and energetics. Oxford University Press, Oxford

Hubbell SP (2001) The unified neutral theory of biodiversity and biogeography. Princeton University Press, Princeton NJ

Hui C (2009) On the scaling pattern of species spatial distribution and association. J Theor Biol 261:481-487

Hui C, Fox GA, Gurevitch J (2017) Scale-dependent portfolio effects explain growth inflation and volatility reduction in landscape demography. Proc Natl Acad Sci U S A 114:12507-12511

Hui C, McGeoch MA (2007) Modelling species distributions by breaking the assumption of self-similarity. Oikos 116:2097-2107

Hui C, McGeoch MA (2008) Does the self-similar species distribution model lead to unrealistic predictions. Ecology 89:2946-2952

Hui C, McGeoch MA (2014) Zeta diversity as a concept and metric that unifies incidence-based biodiversity patterns. Am Nat 184:684-694

Hui C, McGeoch MA, Reyers B, le Roux PC, Greve M, Chown SL (2009) Extrapolating population size from the occupancy-abundance relationship and the scaling pattern of occupancy. Ecol Appl 19:2038-2048

Hui C, McGeoch MA, Warren M (2006) A spatially explicit approach to estimating species occupancy and spatial correlation. J Anim Ecol 75:140-147

Hui C, Richardson DM (2017) Invasion dynamics. Oxford University Press, Oxford

Hui C, Richardson DM, Pyšek P, Le Roux JJ, Kučera T, Jarošík V (2013) Increasing functional modularity with residence time in the co-distribution of native and introduced vascular plants. Nat Commun 4:2454

Jost L, DeVries P, Walla T, Greeney H, Chao A, Ricotta C (2010) Partitioning diversity for conservation analyses. Divers Distrib 16:65-76

Koch LF (1957) Index of biotal dispersity. Ecology 38:145-148

Kunin WE, Harte J, He F, Hui C, Jobe RT, Ostling A, Polce C, Šizling A, Smith AB, Smith K, Smart SM, Storch D, Tjørve E, Ugland Kl, Ulrich W, Varma V (2018) Upscaling biodiversity: estimating the species-area relationship from small samples. Ecol Monogr 88. https://doi.org/10.1002/ecm.1284

Latombe G, Hui C, McGeoch MA (2017) Multi-site generalised dissimilarity modelling: using zeta diversity to differentiate drivers of turnover in rare and widespread species. Methods Ecol Evol 8:431-442 
Latombe G, McGeoch MA, Nipperess DA, Hui C (2016) Zetadiv: functions to compute compositional turnover using zeta diversity. R package version 1.0. https://cran.rproject.org/package=zetadiv. Accessed 20 May 2017

Latombe G, Pyšek P, Jeschke JM, Blackburn TM, Bacher S, Capinha C, Costello MJ, Fernández M, Gregory RD, Hobern D, Hui C, Jetz W, Kumschick S, McGrannachan C, Pergl J, Roy HE, Riccardo Scalera R, Squires ZE, Wilson JRU, Winter M, Genovesi P, McGeoch MA (2017) A vision for global monitoring of biological invasions. Biol Conserv 213:295-308

Law R, Murrell DJ, Dieckmann U (2003) Population growth in space and time: spatial logistic equations. Ecology 84:252-262

Lebrija-Trejos E, Perez-Garcia EA, Meave JA, Bongers F, Poorter L (2010) Functional traits and environmental filtering drive community assembly in a species-rich tropical system. Ecology 91:386-398

Liang J, Crowther TW, Picard N, Wiser S, Zhou M, Alberti G, Schulze ED, McGuire AD, Bozzato F, Pretzsch H, de-Miguel S, Paquette A, Herault B, Scherer-Lorenzen M, Barrett CB, Glick HB, Hengeveld GM, Nabuurs GJ, Pfautsch S, Viana H, Vibrans AC, Ammer C, Schall P, Verbyla D, Tchebakova N, Fischer M, Watson JV, HYH C, Lei XD, Schelhaas MJ, Lu HC, Gianelle D, Parfenova El, Salas C, Lee E, Lee B, Kim HS, Bruelheide H, Coomes DA, Piotto D, Sunderland T, Schmid B, Gourlet-Fleury S, Sonke B, Tavani R, Zhu J, Brandl S, Vayreda J, Kitahara F, Searle EB, Neldner VJ, Ngugi MR, Baraloto C, Frizzera L, Balazy R, Oleksyn J, Zawila-Niedzwiecki T, Bouriaud $O$, Bussotti F, Finer L, Jaroszewicz B, Jucker T, Valladares F, Jagodzinski AM, Peri PL, Gonmadje C, Marthy W, O'Brien T, Martin EH, Marshall AR, Rovero F, Bitariho R, Niklaus PA, Alvarez-Loayza P, Chamuya N, Valencia R, Mortier F, Wortel V, Engone-Obiang NL, Ferreira LV, Odeke DE, Vasquez RM, Lewis SL, Reich PB (2016) Positive biodiversity-productivity relationship predominant in global forests. Science 354:aaf8957

Magurran AE, Henderson PA (2010) Temporal turnover and the maintenance of diversity in ecological assemblages. Phil Tran R Soc B Biol Sci 365:3611-3620

McGeoch MA, Dopolo M, Novellie P, Hendriks H, Freitag S, Ferreira S, Vermeulen W, Kraaij T, Russell IA, Knight MH, Holness S, Oosthuizen A (2011) A strategic framework for biodiversity monitoring in south African National Parks: essay. Koedoe 53:1-10

McGeoch MA, Latombe G (2016) Characterizing common and range expanding species. J Biogeogr 43:217-228

McGeoch MA, Latombe G, Andrew NR, Nakagawa S, Nipperess DA, Roigé M, Marzinelli EM, Campbell AH, Verges A, Thomas T, Steinberg PD, Selwood KE, Hui C (2017) The application of zeta diversity as a continuous measure of compositional change in ecology. BioRxiv. https://doi.org/10.1101/216580

McGill BJ, Dornelas M, Gotelli NJ, Magurran AE (2015) Fifteen forms of biodiversity trend in the Anthropocene. Trends Ecol Evol 30:104-113

Midgley J, Seydack A, Reynell D, McKelly D (1990) Fine-grain pattern in southern cape plateau forests. J Veg Sci 1:539-546

Midgley JJ, Everard DA, Vanwyk G (1995) Relative lack of regeneration of shadeintolerant canopy species in some south African forests. S Afr J Sci 91:7-8

Mucina L, Rutherford MC (2006) The vegetation of South Africa, Lesotho and Swaziland. SANBI, Pretoira

Myers JA, LaManna JA (2016) The promise and pitfalls of beta-diversity in ecology and conservation. J Veg Sci 27:1081-1083

Ricotta C, Pavoine S (2015) A multiple-site dissimilarity measure for species presence/absence data and its relationship with nestedness and turnover. Ecol Indic 54:203-206

Roigé M, McGeoch MA, Hui C, Worner SP (2016) Cluster validity and uncertainty assessment for self-organizing map pest profile analysis. Methods Ecol Evol 8: 349-357

Roura-Pascual N, Sanders NJ, Hui C (2016) The distribution and diversity of insular ants: do exotic species play by different rules? Glob Ecol Biogeogr 25:642-654

Ruiz S (1996) An algebraic identity leading to Wilson's theorem. Math Gazette 80: 579-582

SANParks (2012) Garden route National Park. Management Plan. South African National Parks, Knysna, pp 108

SANParks (2014) Monitoring for sustainable indigenous forest management in the garden route National Park. Scientific Services, South African National Parks, Knysna, p 26

Seifert T, Seifert S, Seydack A, Durrheim G, Kv G (2014) Competition effects in an afrotemperate forest. Forest Ecosys 1:1-15

Seydack AHW (2000) Theory and practice of yield regulation systems for sustainable management of tropical moist natural forests. In: Kv G, Pukkala T, Tomé M (eds) Sustainable forest management. Kluver Academic Publishers, The Netherlands, pp 257-317
Seydack AHW, Durrheim G, Louw J (2011) Spatiotemporally interactive growth dynamics in selected south African forests: Edaphoclimatic environment, crowding and climate effects. For Ecol Manag 261:1152-1169

Shimadzu H, Dornelas M, Magurran AE (2015) Measuring temporal turnover in ecological communities. Methods Ecol Evol 6:1384-1394

Socolar JB, Gilroy JJ, Kunin WE, Edward DP (2016) How should beta-diversity inform biodiversity conservation? Trends Ecol Evol 31:67-80

Soininen J (2010) Species turnover along abiotic and biotic gradients: patterns in space equal patterns in time? Bioscience 60:433-439

Tilman D (2004) Niche tradeoffs, neutrality, and community structure: a stochastic theory of resource competition, invasion, and community assembly. Proc Natl Acad Sci U S A 101:10854-10861

Tuomisto H (2010) A diversity of beta diversities: straightening up a concept gone awry. Part 1. Defining beta diversity as a function of alpha and gamma diversity. Ecography 33:2-22

Van Daalen JC (1991) Forest growth: a 35-year southern cape study. S Afr Forestry J 159:1-10

Van Daalen JC (1993) The value of crown position and form as growth indicators in mixed evergreen forest. S Afr Forestry J 165:29-35

Vaz AS, Kueffer C, Kull CA, Richardson DM, Schindler S, Muñoz-Pajares AJ, Vicente JR, Martins J, Hui C, Kühn I, Honrado JP (2017) The progress of interdisciplinarity in invasion science. Ambio 46:428-442

Vellend M (2016) The theory of ecological communities. Princeton University Press, Princeton, NJ

Volkov I, Banavar JR, Hubbell SP, Maritan A (2003) Neutral theory and relative species abundance in ecology. Nature 424:1035-1037

Volkov I, Banavar JR, Hubbell SP, Maritan A (2007) Patterns of relative species abundances in rainforests and coral reefs. Nature 450:45-49

Von Maltitz G, Mucina L, Geldenhuys C, Lawes MJ, Eeley H, Adie H, Bailey C (2003) Classification system for south African indigenous forests: an objective classification for the Department of Water Affairs and Forestry. Environmentek report ENV-PC 17:1-284

\section{Submit your manuscript to a SpringerOpen ${ }^{\circ}$ journal and benefit from:}

- Convenient online submission

- Rigorous peer review

- Open access: articles freely available online

- High visibility within the field

Retaining the copyright to your article

Submit your next manuscript at $>$ springeropen.com 